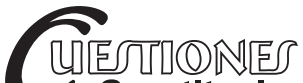 Constitucionales
}

Revista Mexicana de Derecho Constitucional Núm. 40, enero-junio 2019

\section{Declaración de inconstitucionalidad, modulación de efectos y buena fe del Estado en Brasil}

\section{Unconstitutionality Rulings, Effects Adjudication and State's Good Faith in Brazil}

\section{Ana Paula Oliveira ÁvilA*}

RESUMEN: Este artículo presenta un estudio del régimen de modulación de efectos de los actos declarados inconstitucionales por el Tribunal Supremo Federal de Brasil, introducido por una ley innovadora en materia de control de constitucionalidad: la Ley 9868/99. La investigación utiliza la técnica de revisión bibliográfica, legislativa y jurisprudencial con los siguientes objetivos: a) demostrar que la naturaleza de la inconstitucionalidad (nulidad y anulabilidad) no impide reconocer efectos a las leyes inconstitucionales, incluso en los regímenes de control que adoptan el dogma de la nulidad del acto inconstitucional; $b$ ) proponer una teoría interpretativa de la modulación de efectos centrada en los derechos fundamentales y la dignidad humana, y $c$ ) responder, con base en el principio de la buena fe, si el Estado puede, en definitiva, beneficiarse del reconocimiento de efectos de leyes que lesionan derechos fundamentales del sujeto, tales como la libertad y el patrimonio.

Palabras clave: inconstitucionalidad; control de constitucionalidad; tribunal constitucional; modulación de efectos; buena fe; derechos fundamentales.
ABSTRACT: This article presents a study about prospective rulings in the judicial review by the Federal Supreme Court of Brazil, under the provisions of the Law 9868/99. Such statute enabled the Constitutional Court to, under certain circumstances, validate the effects produced by unconstitutional laws. The research is based on doctrine, legislation and jurisprudential review and aims at: a) demonstrating that the nature of unconstitutionality (nullity or annulability) does not prevent the recognition of the effects from unconstitutional laws as valid, even in the judicial review systems where the nullity of the unconstitutional dogma is adopted; b) proposing that the prospective rulings should be addressed through an interpretative theory centered on the fundamental rights and human dignity protection, and c) responding, based on the good faith principle, if Governments should or not benefit from the validation of effects produced by unconstitutional laws when they have damaged fundamental rights, such as freedom and property.

Keywords: Unconstitutional Laws; Judicial Review; Constitutional Court; Effects Modulation; Good Faith; Fundamental Rights.

Doctora en Derecho (UFRGS, Brasil); magíster en Derecho Público (UFRGS, Brasil); catedrática de Derecho Constitucional del grado y Posgrado en Derecho (anapaula. avila@icloud.com). 
SUMARIO: I. Introducción. II. Régimen de efectos de la inconstitucionalidad. III. Las reglas interpretativas que deben orientar la modulación de efectos de leyes inconstitucionales. IV. La cláusula general de la buena fe y su función en el caso objeto de estudio. V. Conclusión. VI. Bibliografía.

\section{INTRODUCCIÓN}

Con la publicación de la Ley 9.868, de 1999, se introdujo oficialmente en el ordenamiento jurídico brasileño la posibilidad de que el Tribunal Supremo Federal modulara los efectos de los actos declarados inconstitucionales en aquellos casos en los que, por razones de seguridad jurídica y excepcional interés social, se justificara dicha medida. Si, por un lado, la ley podía poner un punto final a uno de los debates más acalorados del derecho constitucional sobre la naturaleza del acto inconstitucional (si el acto era nulo o anulable), por otro lado, suscitaba problemas sobre su interpretación en casos concretos relativos al mantenimiento de los efectos de las leyes inconstitucionales. La propuesta de este artículo es debatir sobre uno de estos problemas, con la finalidad de responder, a la luz del principio de buena fe, si el Estado puede beneficiarse de la posibilidad de modular los efectos cuando el Tribunal Supremo declara inconstitucionales leyes estatales que limitan la libertad y el patrimonio de los ciudadanos.

No es un tema sencillo, pues implica, en primer lugar, la superación de la tradicional dicotomía de la teoría general del derecho civil entre acto nulo y anulable y se deduce, a partir de ahí, el régimen de efectos aplicable. Gracias a este estudio, se podrá responder a la cuestión preliminar de saber si se pueden reconocer efectos jurídicos a los actos nulos y en qué condiciones sería posible. Sin embargo, con ello sólo se resuelve parte del problema, ya que aún cabe formularse otra pregunta: ¿a quién debe beneficiar el reconocimiento de los efectos del acto nulo? Para responder a esta cuestión hay que desarrollar una teoría interpretativa que deduzca, a partir de los principios fundamentales de la Constitución, los cánones hermenéuticos adecuados para integrar la norma que permita la modulación de los efectos de los actos inconstitucionales. Dos de estos cánones están relacionados con este estudio, a saber: la dignidad humana y la buena fe.

Las dos cuestiones propuestas exigen comenzar por comprender la disposición que contiene el artículo 27 de la Ley 9.868/99. Esta disposición 
permite que el Tribunal Supremo Federal, por mayoría de dos tercios y por "razones de seguridad jurídica" o "excepcional interés social", reconozca que los efectos iniciales de la declaración de inconstitucionalidad se apliquen de forma parcial (ex tunc relativo o parcial), ex nunc o pro futurum. ${ }^{1}$ Esta autorización revolucionó, en cierta forma, la tradición del Tribunal de declarar la inconstitucionalidad con efectos ex tunc — tradición incorporada al ejercicio de la jurisdicción constitucional brasileña por influencia del derecho norteamericano, que equipara el acto inconstitucional al acto nulo-. Según esta concepción, la cual estuvo presente durante muchas décadas en la jurisprudencia del Tribunal, la declaración de nulidad con efectos ex tunc era la regla y, y a su vez, la posibilidad de modular los efectos temporales de la resolución era algo absolutamente excepcional, que se producía lejos de cualquiera de las limitaciones del artículo 27 de la Ley 9.868/99. ${ }^{2}$

La indeterminación apriorística de los conceptos "seguridad jurídica" y "excepcional interés social" exige una teoría interpretativa que oriente su integración. Así pues, al margen de las reglas interpretativas adecuadas, esta disposición puede acabar siendo utilizada para solapar derechos y garantías constitucionales de los sujetos y favorecer intereses oscuros o pragmatismo político en detrimento de aquéllos. Por ello, es importante responder si el Estado, que es quien ostenta el Poder Legislativo limitador de la autonomía del individuo, puede obtener un beneficio cuando utiliza, de forma ilegítima, dicho poder y dicta normas que vulneran los límites constitucionales.

Pasadas casi dos décadas de vigencia de la Ley, se puede afirmar que el Tribunal sólo se ha esforzado en mantener los efectos del acto incons-

1 Ley 9.868/99, artículo 27, in verbis: “Art. 27. Ao declarar a inconstitucionalidade de lei ou ato normativo, e tendo em vista razões de segurança jurídica ou de excepcional interesse social, poderá o Supremo Tribunal Federal, por maioria de dois terços de seus membros, restringir os efeitos daquela declaração ou decidir que ela só tenha eficácia a partir de seu trânsito em julgado ou de outro momento que venha a ser fixado" "“Cuando se declare la inconstitucionalidad de una ley o acto normativo, y a la luz de razones de seguridad jurídica o excepcional interés social, el Tribunal Supremo Federal podrá, por mayoría de dos tercios de sus miembros, limitar los efectos de dicha declaración o decidir que ésta sólo sea eficaz a partir del momento en que sea firme o de otro momento que determine").

2 Se puede señalar, a modo de ejemplo, el Caso del mantenimiento de los efectos de la norma que creó la gratificación de los magistrados (RE núm. 122.202/MG, STF, Pleno, ponente: Francisco Rezek, 10 de agosto de 1993) y el Caso del mantenimiento de los actos realizados por funcionario de hecho (RE núm. 78549/SP, ponente: Bilac Pinto, 7 de junio de 1974). En el mismo sentido, véase RE núm. 78209/SP, ponente: Aliomar Baleeiro, 4 de junio de 1974; RE núm. 79682/SP, ponente: Aliomar Baleeiro, 4 de junio de 1974, y RE núm. 78533/SP, ponente: Firmino Paz, 3 de noviembre de 1981. 
titucional en aquellos casos que implican la protección de derechos que disfruta el ciudadano gracias a esa Ley, en una de las aplicaciones de la llamada "buena fe objetiva": los derechos se obtuvieron de buena fe y en la expectativa de que fueran legítimamente disfrutados. ${ }^{3}$ De otro modo, en aquellos casos en los que leyes inconstitucionales, durante su vigencia, hayan impuesto limitaciones al ciudadano o hayan estipulado deberes en detrimento de la libertad u otros derechos constitucionalmente inviolables, deben anularse los efectos y devolver a las partes al statu quo ante.

Esta supresión "natural" de los efectos no válidos —o la aplicación de la regla general del efecto ex tunc- se ha rebatido ante el Tribunal Supremo Federal en varios procesos de naturaleza tributaria, que están a la espera de resolución ante este tribunal, en los que la Hacienda solicita la modulación de efectos con el fin de impedir la repetición del pago indebido al contribuyente, argumentando que, si se tiene que devolver el tributo inconstitucionalmente exigido, se causaría un grave perjuicio a la salud financiera del Estado. Se sugiere que se ponderen los derechos de libertad y propiedad del contribuyente — que la Constitución considera inviolables - y la "salud financiera del Estado" — que la Constitución trata sólo de forma implícita-. ${ }^{4}$

3 Esto es lo que sucedió, a modo de ejemplo, en el Caso de la modulación ex nunc de los efectos de norma que creó el complemento de peligrosidad a favor de los policías militares y del cuerpo de bomberos del Distrito Federal (ADI 3791/DF, Pleno, ponente: Ayres Britto, 16 de junio de 2010); el Caso del mantenimiento de las reglas en materia de jubilación y de las prestaciones a funcionarios no efectivos (ADI 3106/MG, Pleno, ponente: Luiz Fux, 13 de agosto de 2015); el Caso del mantenimiento de las reglas en materia de jubilación especial de los policías (ADI 2904/PR, Pleno, ponente: Menezes Direito, 15 de abril de 2009), y el Caso del mantenimiento de los actos procesales realizados por los abogados de oficio en defensa de los funcionarios públicos del RS (ADI 3022-2/RS, Pleno, ponente: Joaquim Barbosa, 02 de agosto de 2004).

4 En la Constitución no existe ninguna norma que eleve expresamente la protección de la salud financiera a la condición de principio constitucional fundamental (algunos de los cuales se recogen en el artículo 1o.) o de objetivo fundamental de la República (artículo 3o.). Sin embargo, se trata de un fin implícito, que se ve garantizado por la imposición de deberes al poder público, al exigir, por ejemplo, la responsabilidad fiscal de los gobernantes, el control del tribunal de cuentas y el equilibrio en las cuentas públicas como principio presupuestario. Por tanto, según la Constitución, la salud financiera y el equilibrio de las cuentas públicas son fines garantizados por la responsabilidad fiscal y no a costa de obligaciones ilegítimas del contribuyente, en la medida en que su patrimonio está expresamente protegido contra efectos confiscatorios (artículo 150, IV) y frente a restricciones al margen del debido proceso constitucional y legal. 
En este contexto, se justifica la importancia de investigar las posibilidades de reconocer efectos a actos nulos y a quién puede beneficiar ese reconocimiento. Para responder a estas cuestiones, el estudio se divide en dos partes. En un primer momento, se analiza el régimen jurídico y jurisprudencial de los efectos de la inconstitucionalidad para, posteriormente, proponer las reglas interpretativas que deben tenerse en cuenta al aplicar la norma que permite la modulación de efectos. En esta segunda parte se podrá sentir la fuerza de la cláusula general de la buena fe en la integración del derecho público brasileño. ${ }^{5}$

\section{RÉGIMEN DE EFECTOS DE LA INCONSTITUCIONALIDAD}

En general, se suele definir el tipo de invalidez que afecta a un determinado acto antes de recurrir al régimen de efectos. Esto implicaría responder si el acto es nulo, con lo que se declararía el acto como "inexistente" $\mathrm{y}$, por consiguiente, se anularían todos los efectos que hubiera producido, o anulable, que potencialmente puede producir efectos que, más tarde, podrían ser eliminados. ${ }^{7}$ Con fundamento en las lecciones de Pontes de Miranda, ${ }^{8}$ he sostenido la tesis de que no se debe identificar nulidad con ineficacia, pues existen actos nulos y anulables eficaces. Asimismo, he defendido que las características que distinguen la nulidad y la anulabilidad se remiten a aspectos ajenos a la cuestión de la falta de validez y que no existe una identidad intrínseca en cada uno de estos tipos de invalidez. ${ }^{9}$ Me explico: en muchas ocasiones, el derecho expresa distinciones relativas a la naturaleza

5 Sobre la buena fe, véase, por todos, Martins-Costa, Judith, A boa-fé no direito privado: critérios para sua aplicação, Madrid-São Paulo, Marcial Pons, 2015.

6 Kaser, Max, Direito privado romano, Lisboa, Fundação Calouste Gulbenkian, 1992 , pp. 80 y 81 . Este régimen se debe al hecho de que los romanos no distinguían entre nulidad e inexistencia. Por ello, tenemos la afirmación de Pontes de Miranda: "Cualquier persona podía alegar que el acto es nulo, porque este no existía, no era". Pontes de Miranda, Francisco Cavalcanti, Tratado de direito privado. São Paulo, Revista dos Tribunais, 1983 , t. 4 , p. 28.

7 Michelon Júnior, Cláudio Fortunato, "Ensaio sobre a história, as possibilidades e os limites de uma teoria das invalidades dos atos jurídicos", Revista do Ministério Público do Rio Grande do Sul, Porto Alegre, núm. 40, enero-junio de 1998, pp. 67 y 68.

8 Pontes de Miranda, Francisco Cavalanti, op. cit., pp. 23 y 29, “[L]a distinción entre nulidad y anulabilidad es una creación técnica".

9 Oliveira Ávila, Ana Paula, A modulação de efeitos temporais pelo STF no controle de constitucionalidade, Porto Alegre, Livraria do Advogado, 2009, p. 31. 
misma de las cosas (plano ontológico), como al momento de distinguir entre una cosa mueble y una inmueble, a fin de dispensar un tratamiento adecuado a cada una de estas situaciones. Otras veces, las distinciones son elaboraciones doctrinales (metadiscurso) o derivan directamente del derecho objetivo (discurso), sin corresponder a cualidades identificables en la naturaleza de las cosas, pues se trata de creaciones normativas. Éste es el caso de la distinción entre acto nulo y acto anulable: será nulo todo aquello que el legislador así defina, al igual que anulable. Un ejemplo ilustra esta circunstancia: la simulación, en el Código Civil brasileño de 1916, recibía el tratamiento de un acto anulable (artículo 147, inciso II), mientras que en el vigente Código Civil brasileño de 2002, el mismo vicio se considera causa de nulidad (artículo 167) por decisión legislativa. ${ }^{10}$

Estas observaciones interesan en la medida en que, durante décadas, los constitucionalistas han debatido sobre la naturaleza de los actos inconstitucionales, buscando argumentos perentorios para clasificarlos como acto nulo ${ }^{11}$ o acto anulable, ${ }^{12}$ sin que ni una norma (de cualquiera de las Constituciones brasileñas, ni la vigente ni las anteriores) dispusiera sobre este tipo de invalidez. ${ }^{13}$ Por ello, en Brasil, hasta la Ley 9.868/99, ante la falta

10 Ibidem, pp. 32 y 33.

11 En la línea del sistema de control de constitucionalidad norteamericano, véanse Barbosa, Rui, "Os atos inconstitucionais do congresso e do executivo", Trabalhos jurídicos, Río de Janeiro, Casa de Rui Barbosa, 1962, pp. 70 y ss; Cappelletti, Mauro, O controle judicial de constitucionalidade das leis no direito comparado, 2a. ed., Porto Alegre, Fabris, 1992, pp. 47 y 48; Willoughby, W. W., The Constitutional Law of the United States, Nueva York, 1910, vol. 1, pp. 9 y 10; Gandra da Silva Martins, Ives y Ferreira Mendes, Gilmar, Controle concentrado de constitucionalidade, São Paulo, Saraiva, 2001, p. 313.

12 En la estela del pensamiento de Hans Kelsen sobre el sistema de control de constitucionalidad establecido en la Constitución austríaca de 1920 (Teoria pura do direito, 3 a. ed., trad. de João Baptista Machado, São Paulo, Martins Fontes, 1991, p. 287), destacan los siguientes autores brasileños: Bonavides, Paulo, Curso de direito constitucional, 9a. ed., São Paulo, Malheiros, 2000, p. 301; Brito Machado, Hugo de, "Declaração de inconstitucionalidade e direito intertemporal", Revista Dialética de Direito Tributário, núm. 57, 2000. p. 76, Macedo Nery, Regina Maria Ferrari, Efeitos da declaração de inconstitucionalidade, 4a. ed., São Paulo, Revista dos Tribunais, 1999, pp. 125 y 126.

13 De forma oportuna, en 2009, critiqué: "Es interesante cuestionarse sobre cómo la regla de la nulidad asumió la condición de dogma en la tradición brasileña. Pues, constatada la existencia de dos sistemas diferentes de control de constitucionalidad de las leyes - modelo austríaco, abstracto, y modelo norteamericano, concreto- $\mathrm{y}$, respectivamente, de dos formas distintas de atribución de efectos - ex nunc y ex tunc-, no se podría, de forma absoluta y a priori, negar validez a una u otra forma tratar los efectos. Considerando que, en Brasil, desde la Enmienda Constitucional no. 16, de 26 de noviembre de 1965, 
de una norma específica, el régimen de los efectos de los actos inconstitucionales derivaba de la tradición jurisprudencial del Tribunal Supremo Federal, creada a partir de la interpretación del principio de supremacía de la Constitución y su correlativo "dogma de la nulidad inconstitucional", por lo que

[los] actos inconstitucionales son, por eso mismo, nulos y, en consecuencia, carentes de cualquier carga de eficacia jurídica... La declaración de inconstitucionalidad de una ley alcanza, incluso, a los actos pasados realizados con base en ella, pues el reconocimiento de ese vicio jurídico supremo, que infecta de total nulidad los actos emanados del poder público, no protege las situaciones constituidas bajo su égida e inhibe - ante su inaptitud para producir efectos jurídicos válidos - la posibilidad de invocar cualquier derecho. ${ }^{14}$

El artículo 27 de la Ley 9.868/99 excepcionó esta concepción. El legislador pretendió regular los efectos derivados de la declaración de inconstitucionalidad estableciendo la prerrogativa del Tribunal Supremo Federal, por mayoría de dos tercios y con fundamento en razones de seguridad jurídica o excepcional interés social, de limitarlos o determinar que las declaraciones de inconstitucionalidad sólo produzcan efectos a partir de la publicación de la resolución (ex nunc) o de otro momento que determine (pro futurum).

De este modo, se creó un régimen jurídico que acomodaba la tradición jurisprudencial y establecía un nuevo sistema, en el que la retroactividad de los efectos deberá convivir con las excepciones legalmente establecidas. Parece claro que, ante la falta de normas constitucionales sobre la materia o de atributos ontológicos que correspondan a los tipos de invalidez, el legislador ordinario pueda establecer normativamente dicho régimen. En la regulación elegida,

el legislador se alejó de un modelo rígido y absoluto que obligaba a la definición, por una u otra naturaleza jurídica, que se atribuía a la inconstitucio-

a la Constitución de 1946, los dos modelos de control — abstracto y concentrado- funcionan de forma paralela, no deja de sorprender la formación del dogma de la nulidad de la ley inconstitucional, que hizo de la retroactividad de los efectos de la declaración un imperativo inamovible" (Oliveira Ávila, Ana Paula, op. cit., p. 45).

14 ADIQO 652/MA. Ponente: Celso de Mello, 2 de abril de 1992. Esta orientación sigue, entre otros, el precedente de 1977 (Representación núm. 971, Pleno, ponente: Djaci Falcão, 3 de noviembre de 1977). 
nalidad. Pues, en cuanto a los efectos, la disposición permite que se regulen como si el acto inconstitucional fuera nulo, como si fuera anulable o como si fuese "todavía válido". ${ }^{15}$

Esta solución es adecuada para ajustar una serie de problemas que derivan de la adopción de un régimen rígido relativo a esta cuestión. Esto se cumple con observar que en el sistema norteamericano de control, en el que el acto inconstitucional se considera nulo desde el célebre asunto Marbury contra Madison, que conoció el Tribunal Supremo norteamericano en 1803 (en un sistema que se construye a partir de la jurisprudencia como expresión del common law), el dogma de la nulidad ya fue objeto de flexibilización en situaciones en las que la casación de los efectos de la inconstitucionalidad causaría un grave perjuicio a la seguridad jurídica. En el asunto Chicot County Drainage Dist. contra Baxter State Bank, de 1940, el juez Hughes ya había anotado que "the past cannot be erased by a new judicial declaration", ${ }^{16}$ y el asunto Linkletter contra Walker, de 1965, fue un claro ejemplo en este sentido, al considerar que la naturaleza de los efectos de la declaración de inconstitucionalidad — si son retroactivos o prospectivos - es una cuestión de política judicial (judicial policy), de forma que corresponde al Poder Judicial, a partir de la valoración de las circunstancias y particularidades de cada caso concreto, determinar si los efectos se producen ex tunc o ex nunc. ${ }^{17}$

A su vez, en el sistema austríaco, en el que el acto inconstitucional se caracterizó como anulabilidad, con la consecuente conservación de los efectos producidos hasta el momento de su anulación (ex nunc), el Tribunal Constitucional austríaco recibió (mediante una reforma constitucional llevada a cabo entre 1975 y 1976) la facultad de poder adoptar distintas fórmulas con relación a los efectos temporales, que pueden determinarse ex tunc, ex nunc o pro futurum (cuando se aplaza el término inicial, aunque no durante más de un año). ${ }^{18}$

15 Oliveira Ávila, Ana Paula, op. cit., p. 22.

16308 U.S. 371 (1940). En seguida: “... These questions are among the most difficult of those which have engaged the attention of courts, state and federal, and it is manifest from numerous decisions that an all-inclusive statement of a principle of absolute retroactive invalidity cannot be justified".

17381 U.S. 618 (1965).

18 Artículo 140, apartado 5 de la constitución Austríaca: “The judgment by the constitutional court which rescinds a law as unconstitutional imposes on the federal chancellor or the competent state-governor the obligation to publish the rescission without delay. 
Estos datos, tomados de los sistemas que inspiraron la conformación del control judicial de constitucionalidad en Brasil, ya podrían justificar la superación del criterio de que optar entre nulo y anulable es algo indispensable para establecer el régimen de efectos de los actos inconstitucionales. Es razonable que el legislador, en un sistema como el brasileño, en el que coexisten los sistemas difuso y concentrado de control, haya fijado un régimen inclusivo de diferentes formas de orientar los efectos, ajeno a esta clasificación tradicional de los tipos de invalidez. Con arreglo al régimen jurídico de la Ley 9.868/99, aunque se trate de la inconstitucionalidad de un acto nulo, se le podrán reconocer efectos (ex nunc) e, incluso, tolerarlos durante el plazo fijado por el tribunal (pro futurum). Por tanto, la anulación sigue siendo la regla, pero admitirá excepciones. De este modo, se puede responder a la cuestión inicial afirmando que se pueden reconocer efectos jurídicos a los actos nulos, siempre que se satisfagan las siguientes condiciones: mayoría cualificada de dos tercios del Tribunal Supremo y motivación en razones de seguridad jurídica o excepcional interés social.

No obstante, como se ha afirmado en la introducción, reconocer que es posible mantener la eficacia del acto nulo sólo resuelve parte del problema, pues la ambigüedad de los motivos que lo justifican (razones de seguridad jurídica o excepcional interés social) plantea nuevas cuestiones, relativas a la interpretación de estos conceptos indeterminados y a los sujetos que pueden beneficiarse de las nulidades que justifican que se invaliden las leyes en una determinada situación.

\section{LAS REGLAS INTERPRETATIVAS QUE DEBEN ORIENTAR LA MODULACIÓN DE EFECTOS DE LEYES INCONSTITUCIONALES}

Esta prerrogativa del Tribunal Supremo para determinar el reconocimiento y la conservación de efectos de actos inconstitucionales generó, e incluso

This applies analogously in the case of a pronouncement pursuant to Paragraph 4. The rescission enters into force on the day of publication if the Court does not set a deadline for the rescission. This deadline may not exceed one year". Véase en concordancia con el apartado 7: "If a law has been rescinded on the score of unconstitutionality or if the constitutional court has, pursuant to Paragraph 4, pronounced a law unconstitutional, all courts and administrative authorities are bound by the court's decision. The law shall, however, continue to apply to the circumstances effected before the rescission, the case in point excepted, unless the court in its rescissory judgment decides otherwise. If the court has in its rescissory judgment set a deadline pursuant to paragraph 5, the law shall apply to all the circumstances effected, the case in point excepted, till the expiry of this deadline". 
genera, una gran inquietud en quien pretende estudiar los derechos fundamentales. En definitiva, dada la regulación que el texto legal hace de la materia, el Tribunal Supremo puede determinar los efectos del acto no válido, algo que puede producirse "tanto en perjuicio de los derechos individuales, como de forma a garantizar la protección de bienes jurídicos, derechos, garantías y principios fundamentales de rango constitucional". ${ }^{19}$ Todo dependerá de cómo se concrete la disposición, los argumentos invocados en la definición concreta de los conceptos abstractamente indeterminados y del sujeto que se beneficie de los efectos que se reconozcan.

La primera norma que se observa en la interpretación de las razones de seguridad jurídica y excepcional interés social es el "postulado de la supremacía de la Constitución". ${ }^{20}$ Para garantizar que no se rompa la supremacía, parece lógico afirmar que la aplicación del artículo 27 de la Ley 9.868/99 sólo será compatible con la Constitución cuando

...su aplicación revele la confrontación entre, al menos, dos normas constitucionales, a saber: (norma X) la norma violada por la ley infraconstitucional y (norma Y) la norma que protege las situaciones que se formaron por causa y durante la vigencia de la ley inconstitucional. Este es el material que hay que ponderar. Atribuir efectos distintos a la regla (ex tunc) solo es posible cuando la mejor forma de resolver esta confrontación, de acuerdo con una comprensión global de la Constitución, sea dando prevalencia a la segunda norma $(\mathrm{Y})$ sobre la primera $(\mathrm{X}){ }^{21}$

En otras palabras, ante la declaración de inconstitucionalidad sólo se podrá modificar el efecto ex tunc cuando se sobreponga la "validez de una norma también constitucional" - la norma que protege los bienes que se mantienen gracias a la determinación de efectos ex nunc, ex tunc parcial (reducido) o pro futuro de la resolución-. Ello impide, por consiguiente, interpretaciones casuísticas que consideren intereses meramente políticos

19 Oliveira Ávila, Ana Paula, op. cit., p. 62.

20 Sobre la condición de postulado, y no de principio, de la supremacía de la Constitución, véase Oliveira Ávila, Ana Paula, op. cit., p. 65. Aquí se adopta el concepto de postulado normativo aplicativo propuesto por Ávila, Humberto, Teoria dos princípios: da definição à aplicação dos princípios jurídicos, 17a. ed., São Paulo, Malheiros, 2016, p. 163. Hay una edición española de esta obra: Ávila, Humberto, Teoría de los princípios, Madrid-Barcelona-Buenos Aires, Marcial Pons, 2011.

21 Oliveira Ávila, Ana Paula, op. cit., pp. 66 y 67. 
o pragmáticos en detrimento de las normas constitucionales. Introducir en el debate intereses ajenos a la Constitución rompería con su supremacía, lo que es incompatible con las democracias constitucionales legítimas. Como ya tuve ocasión de afirmar, "la gran cuestión es demostrar en qué situaciones mantener los efectos de norma inconstitucional también es el medio de proteger la supremacía de la Constitución". ${ }^{22}$

Empero, la delimitación del debate al ámbito constitucional no encauza completamente el problema cuando se trata de una Constitución analítica y compromisoria, como es el caso de la brasileña, que presenta una lista bastante amplia de principios, fines, competencias, garantías, derechos e intereses que, con frecuencia, están en una situación de tensión. En este contexto, la tesis defendida es la de que la modulación de efectos sólo será válida cuando el proceso hermenéutico de integración favorezca los derechos fundamentales, tanto individuales como colectivos.

La fluidez en la significación abstracta de las expresiones "razones de seguridad jurídica" y "excepcional interés social" hace que el intérprete realice la integración de la norma a la luz de los elementos del caso concreto. Esta integración se lleva a cabo, por lo general, recurriendo al pensamiento tópico (problemático), propuesto por Theodor Viehweg, en el que se ponderan los topoi pertinentes al caso. Contribuyen a este proceso los valores, los intereses, los bienes, las pautas y los argumentos materiales que el intérprete puede obtener en el proceso, a partir de la problematización del conflicto, los cuales pueden guiarlo en la elección de las normas y su comprensión. ${ }^{23}$ Sin embargo, la selección de dichos topoi no se produce libremente, máxime porque deben referirse al derecho objetivo a fin de permitir la sindicabilidad de la decisión. En este punto, Larenz, ya hace tiempo, afirmaba que las normas que implican una dimensión valorativa del intérprete postulan un procedimiento intersubjetivamente controlable, presuponiendo que

...el juez concrete y especifique las directrices y los criterios de valoración que previamente le da la ley, pero también el derecho jurisprudencial, ante la situación de hecho que hay que juzgar, que precise y complemente, punto por punto, la situación de hecho teniendo en cuenta los puntos de vista jurí-

22 Ibidem, p. 69.

23 Larenz, Karl, Metodologia da ciência do direito, 2a. ed., Lisboa, Fundação Calouste Gulbenkian, 1989, p. 166. 
dicos que considere en su caso adecuados, y ello en la justa medida y hasta el punto en que no se ofrezca nada más para una decisión justa del caso. ${ }^{24}$

Judith Martins-Costa observa que el razonamiento tópico ejerce un papel relevante a la hora de delimitar el significado de la cláusula general de la buena fe. Apoyada por Zielinski y Viehweg, esta autora afirma que la tópica es "el arte de tener presentes en cada situación vital las razones que recomiendan y desaconsejan dar un determinado paso - bien entendido, en ambos sentidos, tanto de las razones a favor como las razones en contra-". Estas razones relevantes son los tópicos. Estos tópicos están formados por puntos de vista y, por ello, no están previamente fijados y ordenados, de tal forma que el intérprete los seleccionará de manera más o menos arbitraria. Empero, esta arbitrariedad en la elección de los tópicos que orientarán el proceso de resolución no es absoluta, pues se condiciona a su función, que, para Viehweg, consiste en "servir a un debate de problemas", e incluso porque, aunque no se tenga una ordenación sistemática de los tópicos, no se podrá, por ello, considerarlos desordenados, es decir, existe la posibilidad de ordenarlos en ciertos "repertorios de puntos de vista" o "catálogos tópicos" previamente organizados. ${ }^{25}$

Esta idea inspira la siguiente propuesta hermenéutica, cuyo objetivo es orientar al exégeta en la interpretación de la norma que permite modular los efectos y que se expresa en un conjunto de tópicos previamente organizados:

\section{Sólo caben en el debate tópicos filtrados por la Constitución}

La primera propone, como ya se ha visto, circunscribir los topoi al ámbito de las cuestiones presentes en la Constitución, a fin de resguardar la supremacía constitucional. Puede identificarse un sistema interno en los principios fundamentales que estructuran el sistema, tales como la legalidad y la seguridad jurídica, que ofrecen parámetros para jerarquizar los argumentos que se pueden utilizar para justificar la decisión. Como resultado de este sistema se pueden aducir otros tópicos.

24 Ibidem, p. 167, en este caso citando a Fikentscher.

25 Martins-Costa, Judith, A boa-fé no direito privado: sistema e tópica no processo obrigacional, São Paulo, Revista dos Tribunais, 1999, p. 360. 


\section{Entre varios argumentos, los institucionales prevalecen sobre los no institucionales}

Se entiende por "argumentos institucionales" "aquellos construidos a partir del ordenamiento jurídico vigente, tanto de su lenguaje textual y contextual como de sus valores y estructura", ${ }^{26}$ que abarcan tanto los argumentos lingüísticos (que se refieren al significado del texto que expresa la norma jurídica) como los argumentos sistemáticos (que permiten la contextualización y la combinación del texto con los demás elementos del sistema jurídico). Estos argumentos funcionan para la comprensión inicial de la norma, teniendo en cuenta los sentidos gramatical y semántico del texto a partir de su relación con elementos textuales derivados de la jurisprudencia o la doctrina, que forman parte de un fondo de conocimiento y convicciones comunes compartido a partir de la experiencia constitucional. ${ }^{27}$

En contraposición, existen argumentos no institucionales, que son aquellos que

...no hacen referencia a los modos institucionales de existencia del Derecho. Se refieren a cualquier otro elemento distinto del ordenamiento jurídico. Son argumentos meramente prácticos que dependen de un juicio, que lleva a cabo el propio intérprete, desde puntos de vista económicos, políticos o éticos. ${ }^{28}$

Aquí reside el peligro de los argumentos meramente retóricos, pragmáticos o consecuencialistas, como, en el caso de no atribuir efectos ex tunc a

${ }^{26}$ Ávila, Humberto, "Argumentação jurídica e a imunidade do livro eletrônico", Revista Diálogo Jurídico, núm. 5, 2001, p. 7, disponible en: http://www.direitopublico.com.br.

27 Müller, Friedrich, Discours de la mèthode juridique, trad. de Oliver Jouanjan, París, PUF, 1993, p. 257. Más adelante, en la p. 263, Müller denomina a estas "reglas" no escritas "estándares" en derecho constitucional. La lección de Müller corrobora la regla inicial que determina el filtrado de los argumentos relacionados con las normas constitucionales (regla " $i$ "): "[E]l Derecho constitucional consuetudinario, como complemento de la Constitución, solamente puede existir de acuerdo con los fundamentos y las reglas particulares de esta misma Constitución, sólo existe praeter constitutionem. Es una consecuencia de optar por el Derecho constitucional codificado, así como de la función limitadora de los textos constitucionales escritos. Ni el establecimiento, ni la concreción del derecho infraconstitucional, ni la formación ni la concreción del Derecho constitucional no escrito pueden superponerse a los límites inherentes de la forma lingüística de la Constitución escrita" (traducción propia).

28 Ávila, Humberto, “Argumentação jurídica...”, op. cit., p. 18. Sigue el autor: "[L]as consecuencias perjudiciales de una determinada interpretación y la necesidad de considerar los planos de gobierno se enmarcan aquí". 
la declaración de inconstitucionalidad para evitar un "torrente de demandas individuales" o un "desfalco millonario en las cuentas públicas". En el ámbito tributario, este tipo de modulación acabaría instituyendo la "inconstitucionalidad útil”, expresión acuñada por el magistrado Marco Aurélio para referirse al sesgo estimulante de la atribución de efectos ex nunc a las leyes inconstitucionales:

En el momento que el Supremo no declara — como debe hacer - inconstitucional una ley desde su origen, incentiva que las cámaras legislativas de Brasil dicten normas al margen de la Carta Federal, para que subsistan, con el paso del tiempo, las situaciones constituidas — que, desde la perspectiva del perfeccionamiento, no se muestran así-, las cuales, posteriormente, serán apoyadas, aunque de forma indirecta, por la modulación. Acaba surgiendo una nueva institución, como ya he señalado en el Pleno — de la inconstitucionalidad útil—, a la que, además, contribuye el atraso de la maquinaria judicial. ${ }^{29}$

Por ello, la tríada legalidad-democracia-seguridad, que es la base del sistema constitucional, fundamenta la regla de prevalencia de los argumentos institucionales sobre los no institucionales, que determina que estos últimos sólo se tengan en cuenta cuando fluyan en la misma dirección que los primeros, a fin de únicamente reforzar la decisión. En este sentido, no se admite que argumentos políticos o pragmáticos puedan, por sí solos, motivar una resolución. Esto es consecuencia de la jerarquización formal del sistema jurídico, en la medida en que un argumento gramatical contextualizado en el contenido literal de una disposición constitucional vale más que una razón meramente pragmática que no alcanza la Constitución.

\section{Entre los argumentos institucionales, los inmanentes prevalecen sobre los transcendentes}

Como se ha visto, los argumentos no son equivalentes en la medida en que tienen una fuerza justificativa distinta. Cuando estamos ante varios argumentos institucionales que llevan a soluciones divergentes, surge una nueva necesidad de jerarquización. Por ello, se distinguen los argumentos institucionales inmanentes (gramaticales y sistemáticos) y transcendentes

29 Recursos de aclaración de sentencia en la ADI 352/RN, STF, Pleno, ponente: Marco Aurélio, de 27 de septiembre de 2015. 
(los argumentos históricos, relativos al momento en que la norma fue concebida, y los argumentos genéticos, que consideran la voluntad del legislador y pueden adquirir una connotación semántica, cuando se considera el significado que el legislador habría atribuido a una determinada expresión al legislar, o una connotación teleológica, cuando se considera cuál es la finalidad que se perseguía al dictar la norma). ${ }^{30}$

Entre los autores contemporáneos de la teoría constitucional, Robert Alexy y Friedrich Müller se ocuparon de organizar la argumentación mediante reglas de prelación entre los diversos tipos de argumentos, que pueden ser semánticos, genéticos, teleológicos, históricos, comparativos y sistemáticos. ${ }^{31}$ Ante esta diversidad, estos autores proponen una jerarquización entre los argumentos, a fin de que algunos prevalezcan sobre otros. ${ }^{32} \mathrm{En}$ este sentido, Alexy propone la siguiente regla (J. 7): "[L]os argumentos que expresan un vínculo con el contenido real del Derecho o la voluntad del legislador histórico prevalecen sobre otros argumentos, a menos que haya fundamentos racionales para otorgar prevalencia a los otros argumentos". ${ }^{33}$

La prevalencia de los argumentos inmanentes frente a los transcendentes deriva de que

...el poder parlamentario es el que tiene representatividad democrática para tomar decisiones; y el respeto a esas decisiones es un elemento necesario del principio de separación de poderes. Los argumentos sistemáticos deri-

30 Ávila, Humberto, “Argumentação jurídica...”, op. cit., p. 17. Para una síntesis analítica al respecto de la teoría de la argumentación jurídica de Robert Alexy, véase, por todos, Atienza, Manuel, As razões do direito. Teorias da argumentação jurídica, São Paulo, Landy, 2000, pp. 234 y ss.

31 Alexy, Robert, Teoria da argumentação jurídica, trad. de Hilda Hutchinson Schild Silva, São Paulo, Landy, 2005, p. 204. Alexy divide los argumentos en seis grupos: los semánticos, que describen el uso del lenguaje; los genéticos, que se refieren a la voluntad del legislador; los teleológicos, relativos a los fines legalmente establecidos; los históricos, que refieren a la reconstrucción del momento de publicación de la norma; los comparativos, que conciernen a la comparación entre los sistemas jurídicos, y los sistemáticos, sobre el sistema jurídico considerado en su conjunto. Es precisamente en este contexto que Alexy propone una jerarquía entre los argumentos, pues considera que algunos de ellos deben prevalecer sobre otros.

32 Müller, Friedrich, Metodologia do direito constitucional, 4a. ed., trad. de Peter Naumann, São Paulo, RT, 2010, p. 97: en caso de contradicción, los elementos metodológicos strictiore sensu, determinados elementos dogmáticos y los elementos del ámbito de la norma preceden a los elementos no directamente referidos a normas.

33 Alexy, Robert, op. cit., pp. 242 y 243. 
van de la idea de coherencia del sistema jurídico, que se deja reconducir a los principios fundamentales del Estado democrático de derecho (art. 1 de la Constitución Federal de 1988), sin los que, en vez de control jurídico del Estado, racionalidad del Derecho por la claridad y la previsibilidad y tutela plena de los derechos, hay arbitrariedad. Los argumentos institucionales transcendentes (argumentos genéticos e históricos), a su vez, no derivan de la fuerza vinculante del poder legislativo. Sólo de forma indirecta pueden reconducirse a él, en la medida en que exploran los trabajos preparatorios del contenido final de los actos legislativos o buscan reconstruir un momento histórico anterior. Los argumentos no institucionales o meramente prácticos ni siquiera indirectamente hacen referencia a la fuerza vinculante del poder legislativo; estos no se dejan reconducir, en consecuencia, a los principios inmanentes al Estado democrático de derecho. ${ }^{34}$

Con ello, si existen argumentos gramaticales y sistemáticos suficientes para la decisión, los históricos y los genéticos tendrán una fuerza meramente persuasiva, si fluyen en el mismo sentido, o no serán pertinentes para la decisión, en caso de que sean contrarios a aquéllos. Aun así, la tensión entre normas constitucionales que protegen intereses en conflicto exige que la jerarquización sea todavía más honda, mediante el reconocimiento de una regla de prelación material, para conflictos internos de la Constitución.

\section{Entre diferentes normas constitucionales en conflicto, prevalecen las que protejan derechos fundamentales}

Con relación a las normas constitucionales, el hecho de que la propia Constitución defina algunas normas como "normas fundamentales" sugiere que reconoce una jerarquía, al menos, axiológica entre sus preceptos. Por ello, en congruencia con el mayor valor que la Constitución atribuye a determinados principios y derechos, deberá reconocerse un mayor peso al argu-

34 Ávila, Humberto, “Argumentação jurídica...”, op. cit., pp. 25 y 26. En el mismo sentido es la orientación de Müller (Discours de la mèthode juridique, cit.), que está de acuerdo con la posibilidad de una jerarquización abstracta que sea acorde con el principio del Estado de derecho (ibidem, p. 322); también considera que los argumentos directamente relacionados con el texto normativo tienen preferencia sobre los argumentos que no estén directamente relacionados con él (ibidem, pp. 320 y 321). Estos últimos "no ofrecen más que una simple función auxiliar, o sugerencias sobre las posibilidades de precisión, determinación o explicación de la norma jurídica y de la norma de decisión que deba establecerse" (traducción propia). Véase, además, ibidem, pp. 323 y 324. 
mento que favorezca, dentro de este contexto, esos mismos principios y derechos (los fundamentales).

Una forma segura de reconocer esa jerarquía axiológica se da por la propia interpretación literal: basta atenerse a aquello que el texto designa como fundamental para tener los valores en cuya protección tendrá que converger la argumentación, en detrimento de aquello que no sea fundamental. Este descompás terminológico no es producto de la casualidad; por tal motivo, se debe, según Souto Maior, ponderar que "los derechos y los deberes individuales y colectivos del artículo 5 se reúnen bajo el título constitucional: «Derechos y garantías fundamentales». Fundamental es ahí lo que está en el fondo de los fundamentos. Lo que sostiene los propios cimientos constitucionales". 35

De hecho, la Constitución Federal, norma central y fundamental del ordenamiento jurídico vigente, mantiene una propuesta teórica de jerarquización de los principios, puesto que es la base empírica de la dogmática constitucional. Según Souto Maior, esta conclusión deriva de la propia realidad normativa:

[F]uera del ordenamiento jurídico constitucional no hay solución: ningún otro criterio para la jerarquización de los principios constitucionales. Principio fundamental, en contraposición a los demás, es el que la Constitución Federal define como tal. Es imposible, por tanto, caracterizar a priori los principios de Derecho constitucional positivo, esto es, prescindiendo de los criterios que ofrece el propio texto constitucional. Esta conclusión se aplica incluso para la jerarquización de los principios constitucionales. Esta solución no puede ofrecerla ningún derecho alternativo. ${ }^{36}$

Al reconocerse esta jerarquía, se sentirán importantes consecuencias en el juego de argumentos que pueden suscitarse para cumplir los conceptos de "razones de seguridad jurídica" y "excepcional interés social". De ella deriva un criterio material de prevalencia, que favorece la protección de los derechos fundamentales del individuo y la dignidad humana frente a otros bienes o intereses, aunque sean constitucionales. Por ello, en la tesis defendida en 2007, afirmé que, en el caso de la modulación de efectos por

35 Souto Maior Borges, José, "Pró-dogmática: por uma hierarquização dos princípios constitucionais”, Revista Trimestral de Direito Público, São Paulo, núm. 1, 1993, p. 145.

36 Ibidem, p. 146. 
parte del Tribunal Supremo, hay que pasar del "discurso" de los derechos fundamentales a la "práctica" de los mismos:

Al tratar los conceptos abiertos del artículo 27, el intérprete debe tener en mente el deber de protección de los derechos fundamentales, así como el deber de optimización del sentido de los preceptos que los prevén, de forma que nunca se utilice la disposición para mantener efectos que lesionen aquellos derechos, que pueda haber producido una norma declarada inconstitucional. Con ello, se quiere afirmar que, cuando la interpretación de razones de seguridad jurídica o excepcional interés social da lugar a un conflicto que tenga en uno de los extremos la protección de los derechos fundamentales del individuo, se debe aplicar la regla de prevalencia de esos derechos, en detrimento de los demás argumentos que puedan invocarse en la cuestión. ${ }^{37}$

Este tópico argumentativo tan sólo especifica la propia eficacia interpretativa de los derechos fundamentales y establece, para el intérprete del derecho, lo mismo que la llamada "eficacia informadora" de la Constitución traduce para el legislador: los preceptos y principios constitucionales deben servir de orientación para la legislación posconstitucional y de directriz para la actividad del legislador ordinario, donde surge la obligación de adecuarse al contenido "material" de la ley ordinaria (y, mutatis mutandis, de las resoluciones judiciales) frente a los preceptos y principios constitucionales. $^{38}$

\section{Entre normas fundamentales en conflicto, prevalecen aquellas que realizan más intensamente la dignidad humana}

El constituyente de 1988 optó por no incluir la dignidad humana en la lista de los derechos y garantías fundamentales, y le atribuyó la condición de principio fundamental. Esta previsión del inciso III del artículo 1o. de la Constitución Federal, según Sarlet, declara explícitamente que el Estado existe en función de la persona y no la persona en función del Estado,

37 Oliveira Ávila, Ana Paula, op. cit., p. 130.

38 Arce y Flórez-Valdés, Joaquín, El derecho civil constitucional, Madrid, Civitas, 1991, p. 170: la eficacia informadora de la Constitución ha sido asumida por la doctrina, gozando de reconocimiento casi general. Larenz ve en esta eficacia una pauta decisiva, tanto para la legislación ordinaria como también para la jurisprudencia. 
pues el individuo es, en esencia, la finalidad principal y no un medio para el Estado. ${ }^{39}$

A la par de la condición de norma, la dignidad sigue operante como un valor fundamental que orienta toda la interpretación jurídica, materializando el principal topos que hay que tener en cuenta, del que se deduce "el imperativo según el cual en favor de la dignidad no debe haber duda". ${ }^{40}$

En suma, el uso de las reglas argumentativas ya llevan a concluir que la modulación de efectos no puede aplicarse en detrimento de los derechos fundamentales ni la dignidad humana, que tienen primacía ante la pregunta final que hay que responder: ¿quién puede beneficiarse del reconocimiento de efectos a actos no válidos? Sobre este particular, la buena fe también juega un importante papel.

\section{LA CLÁUSULA GENERAL DE LA BUENA FE Y SU FUNCIÓN EN EL CASO OBJETO DE ESTUDIO}

En el análisis propuesto sobresale la función hermenéutica de la buena fe, que funciona como una directriz valorativa que distancia esta cláusula de un mero "conjunto de palabras encantadas". ${ }^{41}$ El objetivo es poner en eviden-

39 Sarlet, Ingo Wolfgang, Dignidade da pessoa humana e direitos fundamentais na Constituição Federal de 1988, Porto Alegre, Livraria do Advogado, 2001, p. 67.

40 Ibidem, p. 86. Considerando acertada la premisa de que los derechos fundamentales consisten en densificaciones de la dignidad de la persona, estamos completamente de acuerdo con Sarlet en que dentro de cada derecho fundamental está presente un contenido o, al menos, alguna preeminencia, referente a la dignidad humana. Esto sucede con relación a la igualdad, la libertad y la identidad personal, que se concreta en el respeto a la privacidad, la intimidad, el honor y la imagen, todos principios vinculados a la dignidad de la persona, su integridad física y moral. El propio derecho de propiedad se constituye en una dimensión inseparable de la dignidad, en la medida en que representa una de las condiciones para el ejercicio de los derechos de libertad, así como de los demás derechos vinculados al bienestar del individuo. Sarlet afirma, incluso, que el principio de dignidad sirve como criterio para definir materialmente el derecho fundamental (definición que, en la Constitución Federal de 1988 es abierta, dado el contenido del artículo 5.2), de modo que se considerarían fundamentales todos aquellos derechos cuya realización promueva la dignidad, con independencia de la clasificación formal del artículo 5o. de la Constitución.

41 Martins-Costa, Judith, A boa-fé no direito privado: critérios para sua aplicação, São Paulo, Marcial Pons, 2015, p. 441; en este fragmento cita la expresión original de Felix Cohen. 
cia el carácter orientador, informativo y auxiliar interpretativo ${ }^{42}$ de la buena fe, que señala, en el ámbito de la buena fe objetiva, a diversos axiomas derivados de la interpretación del derecho objetivo que realizan la doctrina y la jurisprudencia, aptos para asistir al operador en la decisión relativa a los efectos que deben reconocerse cuando se está ante actos inconstitucionales.

El locus constitucional de la cuestión se justifica en las razones que esgrime Frotscher, al relacionar el principio de la buena fe con la necesidad de que los poderes públicos protejan la dignidad humana. Fuerte en la doctrina alemana, Frotscher aduce que entre los principales objetivos del principio de dignidad humana está la protección y el respeto al individuo, con la respectiva protección de sus derechos fundamentales, y que tales objetivos no pueden lograrse si el Estado, al intervenir en la esfera social, no asegura la estabilidad y la corrección de su actuación. ${ }^{43}$ En este sentido, parece lógico que uno de los fundamentos de la buena fe sea la seguridad jurídica, de ahí que se afirme que son las dos caras de la misma moneda. Así:

...la buena fe aparece como la raíz individual de la protección de la confianza, que se manifiesta en la idea de que la confianza presupone una necesaria relación personal trabada de un determinado modo. Sin embargo, la seguridad jurídica implica previsibilidad y persistencia tanto del ordenamiento jurídico como de las disposiciones de la autoridad, permaneciendo aquí las relaciones personales en la sombra.

La doctrina alemana más moderna..., sin negar la posible coincidencia de contenido, desplaza la problemática de la fundamentación de la protección de la confianza del campo de la buena fe al campo de la seguridad jurídica o al ámbito propio de los derechos fundamentales. ${ }^{44}$

El poder de intervención en la esfera privada evidencia la desigualdad entre la posición del Estado (que está al mando y puede imponer conductas a los ciudadanos y limitar su libertad mediante leyes) y la del ciudadano, (sujeto obligado al cumplimiento de las leyes creadas por el Estado bajo el apercibimiento de las sanciones en ellas previstas). Se distinguen, según González Pérez, dos mundos: "[L]as Administraciones públicas y los administrados, los que detentan el poder y los que lo sufren, los que mandan

42 González Pérez, Jesús, El principio general de da buena fe en el derecho administrativo, 2a. ed., Madrid, Civitas, 1989, p. 22.

43 Apud García Luengo, Javier, El principio de la protección de la confianza en el derecho administrativo, Madrid, Civitas, 2002, p. 145.

44 Ibidem, pp. 149-151. 
y los que obedecen". ${ }^{45}$ Esta desigualdad se compensa de tres formas: $a$ ) la vigencia de un régimen democrático garantiza que, en teoría, el ciudadano participe indirectamente (y, en algunos casos, directamente) en la elaboración de las leyes que limitan sus libertades; $b$ ) dando forma a la dignidad, existen derechos y garantías que la Constitución reconoce al ciudadano y que son oponibles frente al Estado, tales como la garantía del debido proceso legal, que funciona como límite de las libertades individuales o del patrimonio, y c) el Poder Judicial actúa como garante de estos derechos y garantías, por lo que debe proteger al ciudadano en caso de lesión o amenaza (artículo 5, inciso XXXV, de la Constitución Federal de 1988).

La combinación entre estos elementos justifica la "confianza" del ciudadano en la acción estatal, un elemento central de la buena fe objetiva. Sobre este aspecto, destaca la tesis que sostiene Otto Bachof, quien señala que el principio de protección de la confianza sería un instrumento para compensar la dependencia del individuo frente a la acción estatal, protector de la libertad mediante el mantenimiento de las decisiones estatales que la implementan. Según Bachof:

...cuanto mayor es la coacción proveniente de los poderes públicos, cuanto más, por esto, se ata el comportamiento del individuo, cuanto más dependiente es el individuo en sus propias decisiones y disposiciones de las resoluciones de los poderes públicos, tanto más se le obliga a confiar en la fiabilidad de esas resoluciones estatales. Por ello..., resulta que el poder unilateral de disposición del Estado (sea a través de una Ley, sea a través de una medida administrativa) sólo resulta soportable y conciliable con el Estado de Derecho, si se corresponde con un derecho del individuo a una cierta estabilidad de las medidas estatales. La dependencia, que se ha vuelto existencial, del individuo respecto a las resoluciones de los poderes estatales, debe corresponderse con la posibilidad de confiar en dichas resoluciones... ${ }^{46}$

La creciente dependencia entre el individuo y el poder público es una característica de la sociedad moderna, en la que la satisfacción de muchas

45 González Pérez, Jesús, El principio general de la buena fe en el derecho administrativo, 2a. ed., Madrid, Civitas, 1989, p. 66. Este autor continua señalando: "Entre estos dos mundos existe un abismo insalvable. Se da la desconfianza más absoluta entre el administrado y los administradores... Como antes se dijo, el principio puede contribuir a humanizar las relaciones entre administradores y administrados. Y asimismo constituirá un decisivo instrumento para restablecer la confianza entre estos dos mundos que hoy se nos aparecen como irreconciliables". Ibidem, p. 68.

46 Apud García Luengo, Javier, op. cit., pp. 165 y 166. 
necesidades básicas del ciudadano pasa por el Estado y, por ello, se ejercen amplios poderes de regulación, muchas veces invadiendo las esferas individuales más íntimas. Afirma González Pérez: “[V]ivimos en una sociedad en la que el hombre encuentra limitada su libertad real en proporciones jamás soñadas". Según el autor:

Pues hay que perder la esperanza de recobrar algún día las libertades reales perdidas. Ante las causas profundas e incontrastables que lo han determinado, con independencia de la concepción política reinante, sólo cabe intentar hacer más soportable el yugo de la Administración pública. Y, quizás, no exista vía más eficaz que una aplicación rigurosa del principio de la buena fe, principio de hondo significado ético, exigible en el comportamiento, tanto de los entes oficiales, como de los particulares. ${ }^{47}$

En efecto, la relación entre desiguales implica la noción de confianza o fides, que aquí se expresa como los deberes de "amparo y protección", de acuerdo con Martins-Costa. ${ }^{48}$ Además, esta relación implica la noción de lealtad, con lo que resulta inconcebible que el Estado se vuelva contra el ciudadano cuando ejerce las prerrogativas y los poderes recibidos de la Constitución.

Esta relación caracterizada por la desigualdad nos lleva a discernir dos situaciones: la actividad estatal que implementa derechos fundamentales del individuo (y así debe hacerlo frente al deber general de protección de los derechos fundamentales que le impone la Constitución) y la actividad estatal que limita esos derechos al imponer obligaciones legales a los ciudadanos (y que debe estar estrictamente de acuerdo con la Constitución y el derecho, pues, en definitiva, ésta es nuestro contrato, el "contrato social"). La protección del ciudadano es un deber; por su parte, la limitación de la libertad, una prerrogativa del Estado, cuyo fundamento y la forma de ejercicio están determinados por la Constitución.

En la primera situación, en la que la actividad estatal implementa derechos de los ciudadanos, en la vertiente de la protección de la confianza, se invocará la buena fe para garantizar el mantenimiento de los efectos de los actos realizados a su favor, pese a que se reconozca su falta de validez. Este

47 González Pérez, Jesús, El principio general de la buena fe en el derecho administrativo, 2a. ed., Madrid, Civitas, 1989, pp. 42 y 43.

48 Martins-Costa, Judith, A boa-fé no direito privado: critérios para sua aplicação, São Paulo, Marcial Pons, 2015, p. 49. 
régimen está orientado, por un lado, por la prevalencia de los derechos fundamentales y, por otro, por la buena fe objetiva y la protección de las expectativas legítimamente creadas, que son aspectos indisociables de la seguridad jurídica (uno de los motivos que propician la modulación de efectos por parte del Tribunal Supremo Federal). En este supuesto, la declaración de inconstitucionalidad de una norma que haya atribuido derechos al ciudadano con efecto retroactivo implicaría volver al statu quo ante con relación a dichos beneficios, pero la protección de la confianza (elemento de la seguridad jurídica), al tener fundamento constitucional, puede ponderarse con la norma que justifica la declaración de inconstitucionalidad y obligar a que se asuma el mantenimiento de sus efectos. ${ }^{49}$

Para Almiro do Couto e Silva, la buena fe y su vertiente de protección de la confianza son los que dan contenido al principio de seguridad jurídica - fin pretendido por la modulación de efectos-. Según el autor, se exige la protección de la confianza para que,

...en los vínculos entre el Estado y los individuos, se asegure una cierta previsibilidad de la acción estatal, del mismo modo que se garantice el respeto de las situaciones constituidas con arreglo a las normas impuestas o reconocidas por el poder público, a fin de asegurar la estabilidad de las relaciones jurídicas y una cierta coherencia en la conducta del Estado. ${ }^{50}$

Dicho de otro modo, la formulación de los principios de protección de la confianza y seguridad jurídica puede ser la siguiente: el ciudadano debe poder confiar en que los actos o decisiones públicas, que afectan a sus derechos, están relacionados con efectos duraderos, previstos o calculados con base en las normas jurídicas vigentes. Estos principios se refieren básicamente a: $a$ ) la prohibición de leyes retroactivas; $b$ ) la inalterabilidad de la cosa juzgada, y $c$ ) la tendencial irrevocabilidad de actos administrativos constitutivos de derechos. ${ }^{51}$

De esta forma, señala Couto e Silva, debe considerarse el principio de seguridad jurídica en una doble vertiente: 1) la objetiva, que se refiere a

49 Oliveira Ávila, Ana Paula, op. cit., p. 151.

50 Couto e Silva, Almiro do, "O princípio da segurança jurídica (proteção à confiança) no direito público brasileiro", Revista de Direito Público, Belo Horizonte, año 2, núm. 6, 2004, pp. 7-59.

51 Gomes Canotilho, J. Joaquim, Direito constitucional e teoria da constituição, 4a. ed., Coímbra, Almedina, p. 252. 
la irretroactividad de los actos estatales (incluidos los normativos) y a la protección del derecho adquirido, del acto jurídico perfecto y de la cosa juzgada, consagrados en el artículo 5o., inciso XXXVI, de la Constitución Federal de 1988, y 2) la subjetiva, relativa a la protección de la confianza del ciudadano con relación a la validez de los actos, procedimientos y conductas del Estado, en todo su ámbito de actividades. ${ }^{52}$ En esta línea, destaca la prohibición del venire contra factum proprium, un importante aspecto de la buena fe objetiva que, en apariencia, tiene semejanzas con la protección de la confianza. En virtud del non venire contra factum proprium, se exige que las conductas sean coherentes en el tráfico jurídico, de tal forma que se prohíben conductas contradictorias. ${ }^{53} \mathrm{El}$ mandato del non venire impediría, por consiguiente, que se anularan los actos constitutivos de derechos y se suprimieran los beneficios que se disfrutaron en el pasado por determinación legal. En palabras de Martins-Costa: "su fondo ético se justifica por el rechazo a la malicia de quien adoptó una determinada conducta, contribuyó a un cierto resultado y, después, pretende escapar de los efectos del comportamiento malicioso alegando la propia malicia a la que contribuyó". ${ }^{4}$

Puesto que los axiomas derivados de la buena fe también se van conformado a partir de su aplicación por los tribunales, cabe mencionar que este sentido del principio, para reconocer la estabilidad de los efectos favorables al ciudadano, ya está bien asentado en la jurisprudencia del derecho público europeo $^{55}$ y brasileño. Existen, históricamente, sentencias del Tribunal Su-

52 Ibidem, p. 10.

53 González Pérez, Jesús. El principio general de la buena fe en el derecho administrativo, 3a. ed., Madrid, Civitas, 1999, p. 21.

54 Martins-Costa, Judith, A boa-fé no direito privado: critérios..., cit., p. 629.

55 Para un extenso examen jurisprudencial en el derecho comparado, véase la interesante monografía sobre la protección de las expectativas en la Comunidad Europea de Schonberg, Soren, Legitimate Expectations in Administrative Law, Oxford, University Press, 2000. Schonberg señala que en el derecho europeo se encuentran distintas fórmulas para el problema, bien sea (a) mediante la protección formal de las expectativas (procedural protection of expectations), de modo que se exigen procedimientos que incluyan el principio de contradicción y amplia defensa; (b) ofreciendo protección material de las expectativas (substantive protection of expectations), o (c) mediante compensación o indemnización por las expectativas frustradas (compensatory protection of expectations). A modo de reseña histórica, en un primer momento, la protección de la confianza despertó el interés jurídico ante el poder de revocación de los actos por parte de la administración pública, cuando se afirmó, en el derecho francés, el principio de irrevocabilidad de las decisiones administrativas creadoras de derechos (intangibilité des décisions créatrices de 


\section{premo Federal muy ilustrativas; por ejemplo, el Caso de la irrevocabilidad del acto de nombramiento de un funcionario público, consolidado por el}

droits) a raíz del caso Mme. Cachet (1922). Una decisión que haya creado derechos es irrevocable (intangible), salvo que las leyes o disposiciones explícitamente concedan el poder de revocarla (ibidem, pp. 70 y 71). No obstante, la utilización de este principio está sujeta a condiciones específicas comunes a los derechos inglés, francés y comunitario: la decisión debe ser (a) favorable, (b) incondicional y, salvo en el derecho francés, o (c) comunicada a la persona afectada; además, la jurisprudencia inglesa sugiere que (d) la persona afectada por la decisión debe haber confiado en ésta ("must have relied to his detriment on the decisión") (ibidem, pp. 73-79). Existe aún una fuerte tendencia en el Tribunal de Justicia Europeo de seguir el ejemplo de Alemania, que se centra más en los efectos de la decisión que en la decisión en sí misma. En esta línea, una decisión sería irrevocable si otorgó un beneficio a una persona, sin embargo, no lo sería si impuso una carga. Así, decisiones legales que son favorables para su destinatario no pueden, salvo previsión legal, ser revocadas, sin que importe si la decisión fue ejercicio de acto reglado o discrecional (ibidem, pp. 71-73). En lo que respecta a las decisiones no válidas, inspirado por las jurisprudencias alemana y francesa, el Tribunal de Justicia Europeo ha desarrollado un principio de ponderación que intenta alcanzar un equilibrio entre las necesidades de legalidad y justicia para los individuos que organizan su vida confiando en decisiones que, más tarde, se consideren ilegales (ibidem, pp. 96-101). El autor, a partir del análisis de las resoluciones del Tribunal Europeo, señala cinco condiciones que orientan la decisión sobre la revocación con efectos retroactivos. En primer lugar, se prohíbe la revocación sólo si la persona en favor de quien la decisión se emitió tenía una expectativa legítima de que la decisión definitivamente resolvía el asunto. No obstante, se exige demostrar que el hombre medio ("in possession of the aplicant's general knowledge and expertise") podría razonablemente tener la expectativa de que la decisión pusiera fin al asunto. Una expectativa legítima se aceptará con más facilidad si era difícil percibir la ilegalidad del acto que causó la expectativa. En segundo lugar, si se demostró que la persona tenía una expectativa legítima, la institución debe considerar el interés del individuo que se verá afectado en la decisión. Esto es especialmente importante si la persona contaba financieramente con esta decisión. La tercera condición se refiere a que la importancia o peso del principio de legalidad debe tenerse en cuenta. Cuanto más seria sea la ilegalidad, más probable será la posibilidad de revocación. Una decisión que viola derechos fundamentales está más sujeta a revocación que aquella que manifiesta un defecto de forma o se basa en una interpretación errónea de una legislative provision ambigua. En cuarto lugar, debe tenerse en consideración la forma como los terceros se verán afectados si se mantiene la decisión contraria a derecho. Sin embargo, para tenerlo en cuenta en el momento de la ponderación, el efecto sobre terceros debe ser directo. Por último, el quinto criterio se refiere al tiempo que ha transcurrido entre la decisión y su revocación. La revocación retroactiva debe realizarse dentro de un "plazo razonable". La extensión de este periodo depende de la dificultad en conferirse el defecto de validez que afectaba el acto (ibidem, pp. 89-95). Las conclusiones del autor, empero, no son nada ajenas al observador local, pues están presentes en la doctrina nacional desde hace mucho tiempo. Véase, por todos, Couto e Silva, Almiro do, "Princípios da legalidade da administração pública e da segurança jurídica no Estado de direito contemporâneo", Revista de Direito Público, núm. 84, 1982. 
transcurso del tiempo, ${ }^{56}$ el Caso de la irrevocabilidad de una autorización de transferencia de centro de enseñanza $a^{57}$ y el Caso de la irrevocabilidad de medida cautelar que reconoce la emancipación de un menor. ${ }^{58}$ Con ello, se forma un nuevo axioma: salvo en situaciones extremas, la buena fe determina la irrevocabilidad de la decisión del poder público en la que haya confiado el beneficiario.

La segunda situación es el caso opuesto, en el que el Estado utiliza normas inconstitucionales para limitar derechos del ciudadano y obtiene un beneficio de esas restricciones, tal y como sucede con las normas que establecen de forma inconstitucional el cobro de tributos. En esta situación, cabe analizar si el Estado también puede invocar la seguridad jurídica y la buena fe para mantener las situaciones creadas por leyes restrictivas inconstitucionales. La respuesta negativa surge no sólo como el resultado del proceso argumentativo visto en el apartado anterior, o sea, por la prevalencia de las normas de derechos fundamentales y la dignidad humana, sino también en virtud de los topoi derivados del ámbito de la buena fe.

El fundamento de la seguridad jurídica a favor del Estado y en perjuicio del ciudadano también choca, en un primer momento, con un obstáculo derivado del hecho de que la seguridad jurídica, además, es un derecho fundamental del ciudadano (como se señala en el apartado introductorio del artículo 5o.) oponible al propio Estado. Sobre este particular, el Tribunal Supremo Federal, en la línea del pensamiento constitucional alemán, viene confirmando el criterio de que los derechos fundamentales benefician a los ciudadanos y no al Estado. ${ }^{59}$

Otras líneas argumentativas corroboran esta conclusión. Si utilizamos un lenguaje análogo al del ámbito de las obligaciones o al contractual, para aquellas situaciones en las que se legisla en contra de la Constitución, el Estado no cumple un contrato previo (el contrato social), que autoriza la aplicación de la exceptio non adimpleti contractus para excusar al ciudadano del cumplimiento de la norma inconstitucional. No obstante, como estamos

56 RE núm. 85.179/RJ. STF, Sala 1a., ponente: Bilac Pinto, DJ del 2 de diciembre de 1977.

57 RE núm. 93.752. STF, Sala 1a., ponente: Rafael Mayer, DJ del 22 de abril de 1981, p. 418.

58 RE núm. 92.757. STF, Sala 1a., ponente: Moreira Alves, DJ del 3 de octubre de 1980, p. 731.

59 RE núm. 251.756/SP, ponente: Moreira Alves, de 8 de mayo de 1998. En la doctrina, en defensa de este argumento, véase Schlaich, Klaus, Das Bundesverfassungsgericht: Stellung, Verfahren, Entscheidungen, 4a. ed., Múnich, Verlag C. H. Beck, 1997, p. 102. 
en el campo de las relaciones desiguales (y para estimular la confianza del ciudadano en el sistema), todos los actos normativos nacen con presunción de validez, de tal modo que el ejercicio de la exceptio por parte del ciudadano presupone, en primer lugar, un decreto judicial de inconstitucionalidad $\mathrm{y}$, en segundo lugar, la nulidad de todos los efectos producidos por el acto inconstitucional.

Aquí, la buena fe deberá cumplir uno de sus papeles, complementando la seguridad jurídica en el sentido de proteger la confianza e impidiendo que el autor de un acto no válido pueda beneficiarse de él. La cuestión se relaciona con la cláusula del tu quoque, muy relevante para justificar la tesis propuesta, en el sentido de que el artículo 27 no puede invocarse a favor del Estado cuando, mediante leyes inconstitucionales, viola derechos del ciudadano. ${ }^{60}$ El tu quoque se refiere al ejercicio inadmisible de un derecho cuando "la posición jurídica alegada se haya obtenido mediante una conducta ilegal" (o, en las relaciones contractuales, contraria al contrato). De una forma más generalizada — aunque menos exacta-, señala Franz Wieacker que "sólo la propia fidelidad jurídica puede exigir fidelidad jurídica". ${ }^{61}$

De este modo, se traduce un nuevo axioma: la persona que viola una norma jurídica no puede, sin abuso, ejercer la situación jurídica que esa norma le haya atribuid. ${ }^{62}$ Wieacker considera el tu quoque como una "excepción de la adquisición de un derecho de mala fe". El caso de aplicación más concreto de esta regla es la fórmula - que se encuentra en el ordenamiento brasileño en el artículo 276 del nuevo Código Procesal Civil- ${ }^{63}$ que impide a la parte recurrir, en su defensa, al ordenamiento jurídico cuando él mismo no lo respetó. Está en juego un "vector axiológico intuitivo" que aglutina "una serie de máximas forenses como turpitudinem suam allegans non auditur; equity must come with clean hands; he who wants equity must do equity". ${ }^{64}$ Se condensa una especie de represalia a la infidelidad jurídica,

60 Oliveira Ávila, Ana Paula, op. cit., p. 157.

61 Wieacker, Franz, El principio general de la buena fe, 2a. ed., Madrid, Civitas, 1986 , p. 66.

62 Menezes Cordeiro, Antonio Manuel, Da boa-fé no direito civil, Coímbra, Almedina, 1997, t. II, p. 837. También citado por Martins-Costa, Judith, A boa-fé no direito privado: critérios..., cit., p. 641.

63 Artículo 276 del Codigo Procesal Civil, in verbis: “Quando a lei prescrever determinada forma sob pena de nulidade, a decretação desta não pode ser requerida pela parte que lhe deu causa" ("Cuando la ley prescribe una determinada forma bajo apercibimiento de nulidad, la parte que originó dicha nulidad no puede solicitar que ésta sea declarada").

64 Wieacker, Franz, op. cit., p. 67. 
que significa, para la situación aquí tratada, la infidelidad del Estado con relación a la Constitución que lo ampara y constituye. En este sentido,

...sería incongruente con los dictámenes de la buena fe (objetiva) a más no poder, la solución que permitiera al Estado usar (en este caso, abusar) del poder de legislar en contra de la Constitución — es decir, inconstitucionalísimamente- - y, como premio, aún disponer de la posibilidad de que se mantenga el beneficio logrado en virtud de la ley inconstitucional, muy especialmente cuando dicho beneficio se da en detrimento de los derechos individuales. ${ }^{65}$

Surge así otro axioma —el de que aquel que origina una nulidad no puede beneficiarse de ella- y, con ello, tenemos todos los elementos para justificar las respuestas a las cuestiones formuladas en la introducción de este estudio.

\section{CONCLUSIÓN}

La cuestión inicial propuesta en este estudio era saber si es posible reconocer efectos jurídicos a los actos nulos, en particular a las leyes inconstitucionales, y bajo qué condiciones. Hemos visto que en Brasil se aplica un régimen legislativo que admite esta posibilidad en situaciones excepcionales: cuando razones de seguridad jurídica y excepcional interés social justifiquen que dos tercios de los magistrados del Tribunal Supremo Federal apliquen la modulación de efecto y reconozcan, con ello, la conservación de los actos inconstitucionales. A continuación, se sostuvo una propuesta hermenéutica para integrar las expresiones "razones de seguridad jurídica" y "excepcional interés social", a fin de asegurar que la norma que autoriza la modulación se utilice con el propósito de garantizar los derechos y la dignidad de la persona y no el mantenimiento de una posible lesión de dichos derechos.

Por último, la cuestión relativa al sujeto al que debe beneficiar el reconocimiento de los efectos del acto nulo se ha respondido a partir de la combinación entre la propuesta hermenéutica articulada y la función interpretativa de la dignidad humana y sus confluencias con la buena fe objetiva. De la convergencia entre todos los topoi deducidos, se concluye que el beneficiario de la modulación no podrá ser el Estado, al menos en las si-

\footnotetext{
65 Oliveira Ávila, Ana Paula, op. cit., p. 155.
} 
tuaciones concretas en las que, de las leyes declaradas inconstitucionales, resulten beneficios para el poder público gracias a violaciones de los derechos individuales. En concreto, se ha llamado la atención sobre la cláusula del tu quoque, un importante aspecto del principio de buena fe que reside, según Menezes Cordeiro, en la propia virtud y la ética de las comunidades jurídicamente organizadas. Proponer el tu quoque impide que alguien se beneficie de su propia torpeza, porque, según Menezes Cordeiro, "hiere las sensibilidades básicas de cualquiera - éticas y jurídicas-, que una persona pueda incumplir una orden y, después, exigir a otro que la acate". ${ }^{66}$

La propuesta debe considerarse en la situación objeto de estudio, puesto que el Estado debe ejercer el poder de dictar leyes dentro de los límites de la Constitución y, al llevarlo a cabo, da lugar a la nulidad que decretará el Poder Judicial — éste sería el caso, por ejemplo, del cobro inconstitucional de tributos- Luego, el Estado no podría, mediante ella, obtener ningún beneficio en detrimento del ciudadano, bajo la pena de vulnerar el deber de buena fe.

En este sentido, al tratar con los conceptos abiertos del artículo 27, el intérprete debe tener en mente el deber de protección de los derechos fundamentales, así como el deber de optimizar el sentido de los preceptos que los prevén, de tal forma que nunca se utilice una disposición para asegurar la conservación de efectos que lesionen los derechos que, en su caso, haya producido una norma declarada inconstitucional. De lo contrario, una modulación arbitraria, además de permitir que quien originó la nulidad se beneficie de ella (algo inconcebible), pone al ciudadano, precisamente, en la posición que el derecho y la moral desean evitar: en la condición de un medio del que se sirve libremente el Estado para lograr "sus" fines.

\section{BIBLIOGRAFÍA}

ALEXY, Robert, Teoria da argumentação jurídica, trad. de Hilda Hutchinson Schild Silva, São Paulo, Landy, 2005.

ARCE Y FlóREZ-VALDÉS, Joaquín, El derecho civil constitucional, Madrid, Civitas, 1991.

AtienZA, Manuel, As razões do direito. Teorias da argumentação jurídi$c a$, São Paulo, Landy, 2000.

66 Menezes Cordeiro, A. Manuel, Da boa-fé no direito civil, Coímbra, Almedina, 1997, p. 837. 
ÁvilA, Humberto, “Argumentação jurídica e a imunidade do livro eletrônico”, Revista Diálogo Jurídico, núm. 5, 2001, disponible en: http://www. direitopublico.com.br.

ÁvilA, Humberto, Teoria dos princípios: da definição à aplicação dos princípios jurídicos, 17a. ed., São Paulo, Malheiros, 2016.

BARBosA, Rui, "Os atos inconstitucionais do congresso e do executivo", Trabalhos jurídicos, Río de Janeiro, Casa de Rui Barbosa, 1962.

Bonavides, Paulo, Curso de direito constitucional, 9a. ed., São Paulo, Malheiros, 2000.

BRITO MACHADO, Hugo de, "Declaração de inconstitucionalidade e direito intertemporal", Revista Dialética de Direito Tributário, núm. 57, 2000.

CAPPELletTi, Mauro, O controle judicial de constitucionalidade das leis no direito comparado, 2a. ed., Porto Alegre, Fabris, 1992.

Couto E SiLva, Almiro do, "O princípio da segurança jurídica (proteção à confiança) no direito público brasileiro", Revista de Direito Público, Belo Horizonte, año 2, núm. 6, 2004.

Couto E Silva, Almiro do, "Princípios da legalidade da administração pública e da segurança jurídica no Estado de direito contemporâneo", Revista de Direito Público, núm. 84, 1982.

Gandra da Silva Martins, Ives y Ferreira Mendes, Gilmar, Controle concentrado de constitucionalidade, São Paulo, Saraiva, 2001.

GARCÍA LUENGO, Javier, El principio de la protección de la confianza en el derecho administrativo, Madrid, Civitas, 2002.

Gomes CANotilho, J. Joaquim, Direito constitucional e teoria da constituição, 4a. ed., Coímbra, Almedina.

GONZÁLEZ PÉREZ, Jesús, El principio general de la buena fe en el derecho administrativo, 2a. ed., Madrid, Civitas, 1989.

HANs, Kelsen, Teoria pura do direito, 3a. ed., trad. de João Baptista Machado, São Paulo, Martins Fontes, 1991.

KASER, Max, Direito privado romano, Lisboa, Fundação Calouste Gulbenkian, 1992.

LAREnZ, Karl, Metodologia da ciência do direito, 2a. ed., Lisboa, Fundação Calouste Gulbenkian, 1989.

MACEDo Nery, Regina Maria Ferrari, Efeitos da declaração de inconstitucionalidade, 4a. ed., São Paulo, Revista dos Tribunais, 1999. 
Martins-Costa, Judith, A boa-fé no direito privado: critérios para sua aplicação, Madrid-São Paulo, Marcial Pons, 2015.

Martins-Costa, Judith, A boa-fé no direito privado: sistema e tópica no processo obrigacional, São Paulo, Revista dos Tribunais, 1999.

Menezes Cordeiro, Antonio Manuel, Da boa-fé no direito civil, Coímbra, Almedina, 1997, t. II.

MiCHELON JÚNIOR, Cláudio Fortunato, "Ensaio sobre a história, as possibilidades e os limites de uma teoria das invalidades dos atos jurídicos", Revista do Ministério Público do Rio Grande do Sul, Porto Alegre, núm. 40, enero-junio de 1998.

MüLlER, Friedrich, Discours de la mèthode juridique, trad. de Oliver Jouanjan, París, PUF, 1993.

MüLlER, Friedrich, Metodologia do direito constitucional, 4a. ed., trad. Peter Naumann, São Paulo, RT, 2010.

OliveIRA Ávila, Ana Paula, A modulação de efeitos temporais pelo STF no controle de constitucionalidade, Porto Alegre, Livraria do Advogado, 2009.

Pontes De Miranda, Francisco Cavalcanti, Tratado de direito privado, São Paulo, Revista dos Tribunais, 1983.

SARLET, Ingo Wolfgang, Dignidade da pessoa humana e direitos fundamentais na Constituição Federal de 1988, Porto Alegre, Livraria do Advogado, 2001.

SCHLAICH, Klaus, Das Bundesverfassungsgericht: Stellung, Verfahren, Entscheidungen, 4a. ed., Múnich, Verlag C. H. Beck, 1997.

SCHONBERG, Soren, Legitimate Expectations in Administrative Law, Oxford, University Press, 2000.

SOUTO MAIOR BorGES, José, "Pró-dogmática: por uma hierarquização dos princípios constitucionais", Revista Trimestral de Direito Público, São Paulo, núm. 1, 1993.

WIEACKER, Franz, El principio general de la buena fe, 2a. ed., Madrid, Civitas, 1986.

WilloughBy, W. W., The Constitutional Law of the United States, Nueva York, 1910.

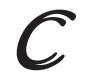

Fecha de recepción: 21 de mayo de 2017.

Fecha de aceptación: 26 de enero de 2018. 